Review Article

\title{
Strategies for neonatal care during the COVID-19 pandemic: a lower middle-income country perspective
}

\author{
Rajat Grover*, Shantanu Shubham, Sriparna Basu
}

Department of Neonatology, All India Institute of Medical Sciences, Rishikesh, Uttarakhand, India

Received: 24 February 2021

Accepted: 01 April 2021

*Correspondence:

Dr. Rajat Grover,

E-mail: groverrajat88@gmail.com

Copyright: ( ) the author(s), publisher and licensee Medip Academy. This is an open-access article distributed under the terms of the Creative Commons Attribution Non-Commercial License, which permits unrestricted non-commercial use, distribution, and reproduction in any medium, provided the original work is properly cited.

\begin{abstract}
COVID-19 has transformed into an all-encompassing pandemic affecting all levels of healthcare throughout the globe. The strains on healthcare systems have been evident even in the most developed countries. Low and middle income countries (LMICs), especially India, find themselves in a precarious situation due to limited resources, poor healthcare worker population ratios and a bigger population. Multiple factors can exponentially increase the actual effect of a pandemic on the vulnerable neonates and infants even though the disease itself may be less lethal for them. The situation was complicated by the implementation of lockdowns. We discuss the implications for neonatal care that such a pandemic has in LMICs and elucidate the strategies we have implemented to provide continuity of care during the pandemic. We also share our experience of providing neonatal care and summarise the patient load witnessed in a specific context of a level-3 NICU in a government multi-speciality hospital of an LMIC.
\end{abstract}

Keywords: COVID-19 pandemic, Low and middle income countries, Neonatal care

\section{INTRODUCTION}

As the year 2019 was nearing its end, a cluster of severe pneumonia cases of unknown origin, linked to a big live animal market were reported from Wuhan, Hubei in China. ${ }^{1}$ The causative organism was later isolated to be a novel virus christened as the 2019-nCoV (novel coronavirus). ${ }^{2}$ Later, WHO rechristened it as severe acute respiratory syndrome coronavirus 2 (SARS-CoV-2) and the disease itself was labelled as coronavirus disease2019 (COVID-19). ${ }^{3}$ The SARS-CoV-2 attained a potential for human-to-human transmission and spread rapidly across the globe which led to the WHO declaring COVID-19 a pandemic on 11 March $2020 .{ }^{4}$

The first laboratory confirmed case in India, a student returning from Wuhan was reported on 30 January $2020 . .^{5}$ This was followed by a surge of patients over the next 9 months, commiserate with the global disease spread. As of 21 February 2021, there were 110,749,023 confirmed cases worldwide and 10,991,695 confirmed cases in India. ${ }^{6}$

The COVID-19 disease causes varying respiratory and gastrointestinal symptoms in adults, especially those with chronic diseases are primarily affected. Only $1.2-2 \%$ reported cases are children. ${ }^{7,8}$ A systematic review, assessing papers published between 1 January 2020 and 1 May 2020 found that $95 \%$ of children were asymptomatic or had mild-to-moderate symptoms. Only $2 \%$ required admission in the intensive care unit with a mortality rate of $0.08 \%$. A total of 25 newborns identified in the review were either asymptomatic or had mild symptoms at the time of diagnosis. ${ }^{9}$

This apparent resistance of children and neonates to the SARS-CoV-2 virus has been explained primarily by the interaction of transmembrane spike glycoprotein (Sprotein) of SARS-CoV-2 virus with the human angiotensin converting enzymes-II (ACE2) cell receptors, 
not abundantly expressed in children and neonates. ${ }^{10}$ The tissue distributions of these receptors is also different from adults. ${ }^{11}$ Another common reason is the immature immune system unable to mount a vigorous cytokine storm. ${ }^{12}$ Neonates and infants may also have only gastrointestinal manifestations due to which they slip under the surveillance radar of screening questionnaires emphasizing on respiratory symptoms. ${ }^{13}$

\section{Why neonates and infants in the LMICs are more vulnerable?}

Health care institutions in LMICs already function under duress due to inadequate manpower and high patient load. In case of an epidemic/pandemic situation, limited resources need to be diverted towards the critically ill and those suffering from the immediate effects of an outbreak.

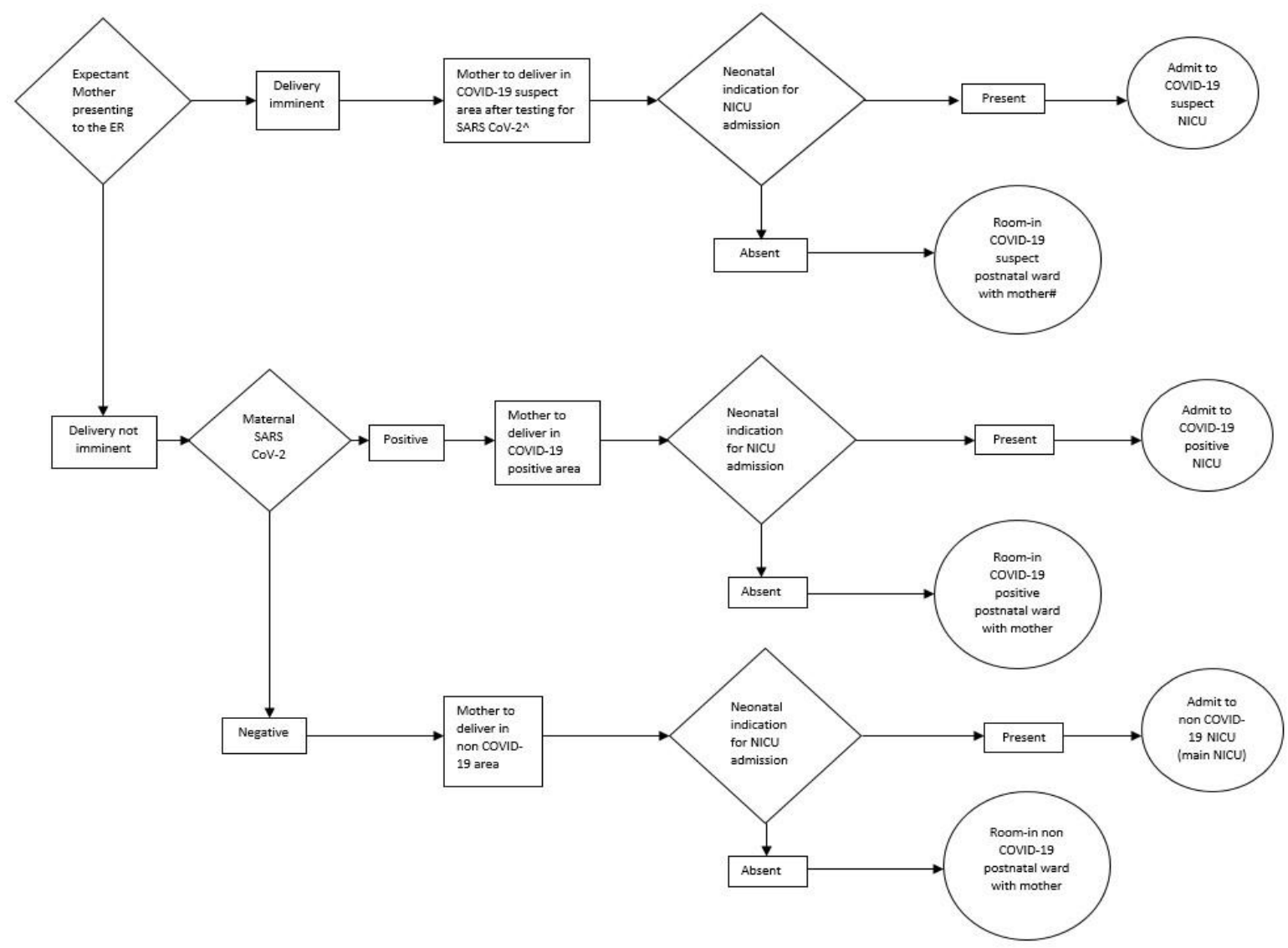

Figure 1: Maternal and neonatal patient flow diagram.

The past Ebola and SARS epidemics revealed a disruption in routine healthcare services with significant decrease in antenatal care, institutional delivery rate and postnatal care of neonates. ${ }^{14,15}$ Dependence of neonates and infants on caregivers (already compromised physically and mentally) makes them vulnerable to the indirect effects of a pandemic like poor availability of nutrition, parental separation, inadequate treatment of common illnesses and predilection towards vaccine preventable diseases. ${ }^{16}$ Country-wide lockdowns also have the potential of disrupting supply chains and decreasing accessibility for the marginalized.

Statistical models predict a $9.8-44.7 \%$ increase in the under-5 mortality rate in 118 LMICs as an indirect effect of the current pandemic due to reduction in the antibiotic coverage for maternal and neonatal indications, reduced institutional deliveries and poor follow-up. ${ }^{17}$ From the
Indian context, this value is massive as the neonatal mortality (23/1000 live-births) is the major contributor to the under-5 mortality (37/1000 live-births). ${ }^{18}$ Our neonatal team aimed to provide wholesome care within the restrictions of resources, infrastructure and manpower while abiding by national and international guidelines. Following is a detailed description of the protocols followed and problems faced while managing neonates during the pandemic.

\section{Context}

Our unit is a 24-bedded tertiary-level referral neonatal intensive care unit (NICU) of a government multispecialty institute in northern India catering to majority of high-risk deliveries of the region. The unit witnesses over 2500 deliveries a year and over 100 NICU admissions (both intramural and extramural) per month. 
There is a closely attached delivery room with 4-bedded newborn stabilization unit and maternity operating rooms. The postnatal ward has 40 beds for the mother and the healthy neonate.

\section{Infrastructure}

The pandemic outbreak generated the need for separate areas for admission of COVID-19 confirmed positive, suspected and non-infected neonates. ${ }^{19}$ As per our institutional policy, three separate hospital blocks have been demarcated for the care of COVID-19 confirmed positive (3 floors), suspected (3 floors) and non-infected patients (6 floors). Two separate blocks of the hospital trauma building, replete with operating rooms, wards, intensive care areas and isolation rooms have been utilized for setting up the COVID-19 suspect and positive areas (jointly called the COVID-19 block). The main NICU is situated in the COVID-19 free area and makeshift NICUs of 4 beds each were set up in the COVID-19 suspect and positive areas. Separate postnatal wards have been set up in the suspected and positive COVID-19 blocks on a separate floor to room-in the asymptomatic neonates with their mother. There are separate rooms for symptomatic and asymptomatic mothers in the postnatal ward. A common operating room for COVID-19 suspected and positive areas has also been set up with arrangements to fumigate and sterilize the operating room between patients. Separate delivery rooms are available for COVID-19 suspected and positive patients.

\section{Manpower}

Separate teams of doctors and nurses have been created for the main NICU, suspected and positive NICU areas. Patients in both the suspected and positive COVID-19 areas are accessed after following full personal protective equipment (PPE) measures as per the standard guidelines. ${ }^{20}$ Social distancing norms are followed by all healthcare professionals, patients and visitors at all times. ${ }^{21}$ All health care staffs were trained in donning, doffing of PPE and in patient-care guidelines under the aegis of our hospital infection control committee (HICC).

\section{Obstetric and neonatal patient flow}

The maternal and neonatal patient flow for intramural neonates is provided in Figure 1.

\section{Delivery room practices}

\section{Mode of delivery}

Obstetric indications dictate the mode of delivery. ${ }^{19}$ The place of delivery is decided according to the COVID-19 status of the mother. The resident and nurse attending deliveries in COVID-19 suspect and positive areas don complete PPE. Newborn care corners are set up 2 metres away from the operating/delivery table, in respective delivery areas. Mothers wear a surgical mask during the entire process of labor. ${ }^{19}$

\section{Cord clamping and skin-to-skin contact}

Delayed cord clamping is practiced in all areas unless there are medical indications for early cord clamping. ${ }^{22}$ Skin-to-skin contact was not practiced earlier in the pandemic but as the pandemic evolved and the riskbenefit ratio appeared to be in favour, this practise has been restarted.

\section{Resuscitation}

Resuscitation procedures are carried out as per the neonatal resuscitation program of the American academy of pediatrics and the guidance issued for management of suspected/confirmed COVID-19 neonates. ${ }^{23}$ Initial steps and further manoeuvres are performed on a Resuscitaire ${ }^{\circledR}$ warmer (Drager $\AA)$, suctioning of airway is not performed routinely (only done if excessive secretions are obstructing the airway) and endotracheal instillation of medications is not practised.

\section{Transport from delivery area}

Most mothers delivering in the COVID-19 suspect area are asymptomatic with no history of close contact with a COVID-19 patient or travel history to a hot spot area but their delivery is conducted in the COVID-19 suspect area primarily due to the unavailability of SARS-CoV-2 test result. These neonates are shifted to the COVID-19 suspect NICU only if they are sick, clinically unstable, $<34$ weeks gestational age or have a birth weight of $<1800 \mathrm{~g}$.

\section{Maternal and neonatal separation}

Well-newborns are roomed-in with mothers irrespective of their and mother's COVID-19 status. Mothers/caretakers are instructed to use surgical mask all times and perform adequate hand hygiene before handling or feeding the neonate. ${ }^{24}$

Neonates having an indication for NICU admission are admitted to the respective NICU area depending on maternal and neonatal COVID-19 status. No parent or caretaker is allowed inside the NICU areas to protect other admitted neonates from postnatal virus exposure which is the predominant mode of infection transmission to the neonates. This seemingly extreme measure is taken to decrease chances of postnatal infections in sick and more vulnerable neonates due to limited isolation areas available for COVID-19 confirmed neonates. Parents are updated over phone and are provided with daily photographs and short videos of the neonate to alleviate separation anxiety. As time progressed and testing facilities were stepped up, caretakers, who were documented to be SARS-CoV-2 negative on RT-PCR testing were allowed access to their neonates for $\mathrm{KMC}$, 
breast feeding and other components of developmentally supportive care from June 2020 onwards.

Neonates who are themselves well but have sick mothers are handed over to a caretaker for care in the postnatal wards once COVID-19 has been ruled out.

Sick extramural neonates are admitted directly to the COVID-19 suspect NICU area and are separated from parents.

\section{Neonatal testing ${ }^{19,24}$}

A 24-hour centralised sample collection and reporting mechanism has been set up to support the increased burden of testing demand. Our hospital also functions as a nodal centre for the region with a turn-over report time of 10-12 hours. Our neonatal testing policy is provided in Table

Table 1: Neonatal COVID-19 testing policy followed in our hospital.

\begin{tabular}{|c|c|c|}
\hline Category & \multicolumn{2}{|c|}{ Practice being followed } \\
\hline \multirow{2}{*}{$\begin{array}{l}\text { Intramural neonates whose } \\
\text { mothers are awaiting SARS- } \\
\text { CoV-2 }\end{array}$} & i. & $\begin{array}{l}\text { Asymptomatic neonates: SARS-CoV-2 testing is not done, carefully } \\
\text { monitoring the neonates for development of symptoms of COVID-19 after } \\
\text { ruling out all other probable causes. }\end{array}$ \\
\hline & & $\begin{array}{l}\text { Symptomatic neonates: Neonates with respiratory distress out of } \\
\text { proportion/unexplained by other causes are tested for SARS-CoV-2 as per } \\
\text { standard guidelines and a repeat testing done after } 5 \text { days for negative and } \\
\text { every fourth day, till admitted, for positive patients. }\end{array}$ \\
\hline \multirow{2}{*}{$\begin{array}{l}\text { Intramural neonates whose } \\
\text { mothers are SARS-CoV-2 } \\
\text { negative }\end{array}$} & i. & Asymptomatic neonates: No testing is done. \\
\hline & & $\begin{array}{l}\text { Symptomatic neonates: Neonates with unexplained/undiagnosed respiratory } \\
\text { distress are tested for SARS-CoV-2. }\end{array}$ \\
\hline $\begin{array}{l}\text { Intramural neonates whose } \\
\text { mothers are SARS-CoV-2 } \\
\text { positive and extramural } \\
\text { neonates }\end{array}$ & & $\begin{array}{l}\text { These neonates are tested for SARS-CoV-2 irrespective of the symptoms; } \\
\text { subsequent testing depends on the neonate's initial SARS-CoV-2 result. }\end{array}$ \\
\hline
\end{tabular}

\section{Feeding practices}

Neonates roomed in with mothers are breastfed after hand hygiene, wearing a surgical mask..$^{25,26}$ For sick mothers, designated caretakers feed expressed breastmilk to the neonate using katori after hand hygiene, wearing a surgical mask. Neonates admitted to the various NICU areas are fed mother's own milk procured from postnatal ward by the nurses either orally or via orogastric/nasogastric tubes. Mothers also feed eligible neonates once they have been documented to be SARSCoV-2 negative.

A nurse trained in lactational counselling is available round the clock for helping mothers in breastfeeding and milk expression. The milk expression room utilising electric breast pumps in NICU has been shut down during the pandemic due to issues of overcrowding.

\section{Respiratory support}

The basic premise of prevention of aerosol spread and precautions while aerosol generating procedures is followed. ${ }^{27}$ All healthcare professionals in COVID-19 positive and suspect areas wear full PPE and those in the non-COVID-19 NICU wear sterile gowns with N-95 respirators as per HICC guidelines.
Manual ventilation, endotracheal intubation and mechanical ventilation

Data from previous epidemics in adults show that ventilation using AMBUß bag or t-piece resuscitator, with or without endotracheal tube in situ, exposes the care provider to significantly lesser aerosols compared to the exposure and risk of viral transmission during the procedure of endotracheal intubation. ${ }^{28}$ Manual ventilation is practised in the same way as in the preCOVID-19 era and so is endotracheal intubation, donning PPE. Use of a video laryngoscope is preferred.

Expiratory filters are used with mechanical ventilators and during manual ventilation to reduce the spread of virus particles. ${ }^{29}$ Appropriate-sized endotracheal tubes are used to ensure minimal leaks. High-frequency oscillatory ventilation used in our unit has been found to be safe from the point of view of infection spread during the previous SARS epidemic. ${ }^{30}$ The suctioning attempts are made only when required.

\section{Non-Invasive ventilation}

There is sufficient evidence from adult studies during previous SARS and H1N1 influenza epidemics of CPAP and NIPPV use for respiratory management in the presence of appropriate infection control measures. ${ }^{30}$ 
Approximately, 20-30\% of the neonates admitted in NICU require non-invasive ventilation at any given point of time. We use nasal continuous positive airway pressure (nCPAP), humidified high flow nasal cannula (HHHFNC) and non-invasive positive pressure ventilation (NIPPV). Nasal prongs are preferred over nasal masks. Though there may be a theoretical risk of dispersion of aerosol, the distance of spread should be minimal for neonates due to low tidal volumes. ${ }^{31} \mathrm{We}$ are using nasal mask for CPAP and NIPPV in our COVID-19 suspect and positive NICUs. There is insufficient evidence currently for the use of HHHFNC in areas where spread of the respiratory virus needs to be controlled, even from the adult literature, due to which we are not using this modality in our COVID-19 NICUs. ${ }^{31}$

\section{Nutritional support}

The usual guidelines for the initiation of breast milk, total parenteral nutrition and advancement of feeds are followed in all the areas caring for the newborn.

\section{Kangaroo mother care (KMC)}

This low-cost intervention has multiple benefits for the stable preterm and the mother. ${ }^{32}$ Due to constraints of space and to prevent exposing the admitted neonates, this practise was discontinued in all the NICUs during earlier months of the pandemic. This had a drastic effect on maternal-neonatal bonding, initiation of breastfeeding and expression of breastmilk. However, the sight of the admitted neonates being comforted in the laps of the nurses was not uncommon in NICU. Eventually, KMC was restarted for all eligible neonates in the non-COVID19 NICU and subsequently in the COVID-19 areas in the later months and is currently provided to all eligible neonates in the hospital

\section{Screening}

We routinely screen all neonates for hypothyroidism, hearing and retinopathy of prematurity in eligible cases. This has been continued in all areas throughout the pandemic.

\section{Discharge}

Stable intramural neonates roomed-in with mothers, in the COVID-19 suspect area are discharged after 24-48 hours to keep beds available for accommodating the high demand of COVID-19 suspect patients. Stable intramural neonates roomed-in with stable COVID-19 mothers in the COVID-19 area are discharged whenever the mother is eligible for discharge. Stable intramural neonates born to sick COVID-19 positive mothers are discharged with a SARS-CoV-2 negative caretaker once it has been documented that the neonate has 2 negative SARS-CoV2 reports. Stable intramural neonates in non-COVID-19 area are discharged at 48-72 hours depending on the mode of delivery and maternal readiness for discharge. ${ }^{19}$

Sick intramural and extramural neonates, admitted in any of the three areas are discharged once they fulfill discharge criteria according to their respective morbidity. All parents and caretakers are counselled in detail at discharge regarding danger signs, feeding, hygiene, use of mask, social distancing and follow up schedule. This time is also utilised to address any queries they might have regarding child-care or follow up. This counselling and teaching session is conducted in a designated lounge area outside NICU complex following social distancing guidelines. Contact details, for resolution of queries telephonically from home, are also shared. ${ }^{24}$

\section{Immunization}

National immunization schedule of India is being implemented during the pandemic. Intramural stable neonates are administered the birth dose vaccinations during hospital stay while unstable and extramural neonates, eligible for vaccination are vaccinated at discharge. ${ }^{33}$ All vaccinations are done at bedside.

For follow-up vaccinations, parents are encouraged to get vaccinations at their neighbourhood local government dispensaries to reduce hospital exposure of the neonate. In case a parent wishes to get follow-up vaccinations at the hospital, they are instructed about the patient flow that begins at the screening area where they have to fill a questionnaire and may need COVID-19 testing and isolation depending on their history and wellness. After getting a clearance from the screening area, they proceed to the vaccination station that is set up in a separate wellventilated wing. Trained nurses administer vaccines at this station with full PPE guidelines.

\section{Follow up and post discharge care}

High risk neonates are followed up telephonically on days 1 (24 hours after discharge), 3, 7 and 10 post discharge and a physical visit is planned at 14 days post discharge or earlier if the neonate merits it. A regular telemedicine OPD, 3 times a week, has also been started to address issues related to neonatal care that parents and caregivers could access.

\section{Our journey so far}

Total number of deliveries conducted in various hospital areas and their SARS Cov-2 status is depicted in Figure 2. Despite best efforts, the rate of physical follow-up visits has been dismal. This was expected in the scenario of a complete lockdown that continued for 3 months. Means of public transportation and movement of private individuals were restricted to the extent that parents feared visiting the hospital for the routine visits even though the government guidelines had a provision for continuation of these services. Another important reason 
may have been the knowledge about presence of SARSCoV-2 positive patients in the hospital and the ensuing fear of contracting the notorious disease. As the lockdown eased and the government-initiated information and education campaigns to push for normalcy with concomitant precautions, follow up rate has increased to some extent but not reached previous levels. However, response to the telemedicine OPD has been very encouraging. These observations are in contrast to the findings of Salvatore et al, who report that $68 \%$ neonates completed the follow up visit at 5-7 days at the three New York presbyterian hospitals in the New York city. ${ }^{34}$

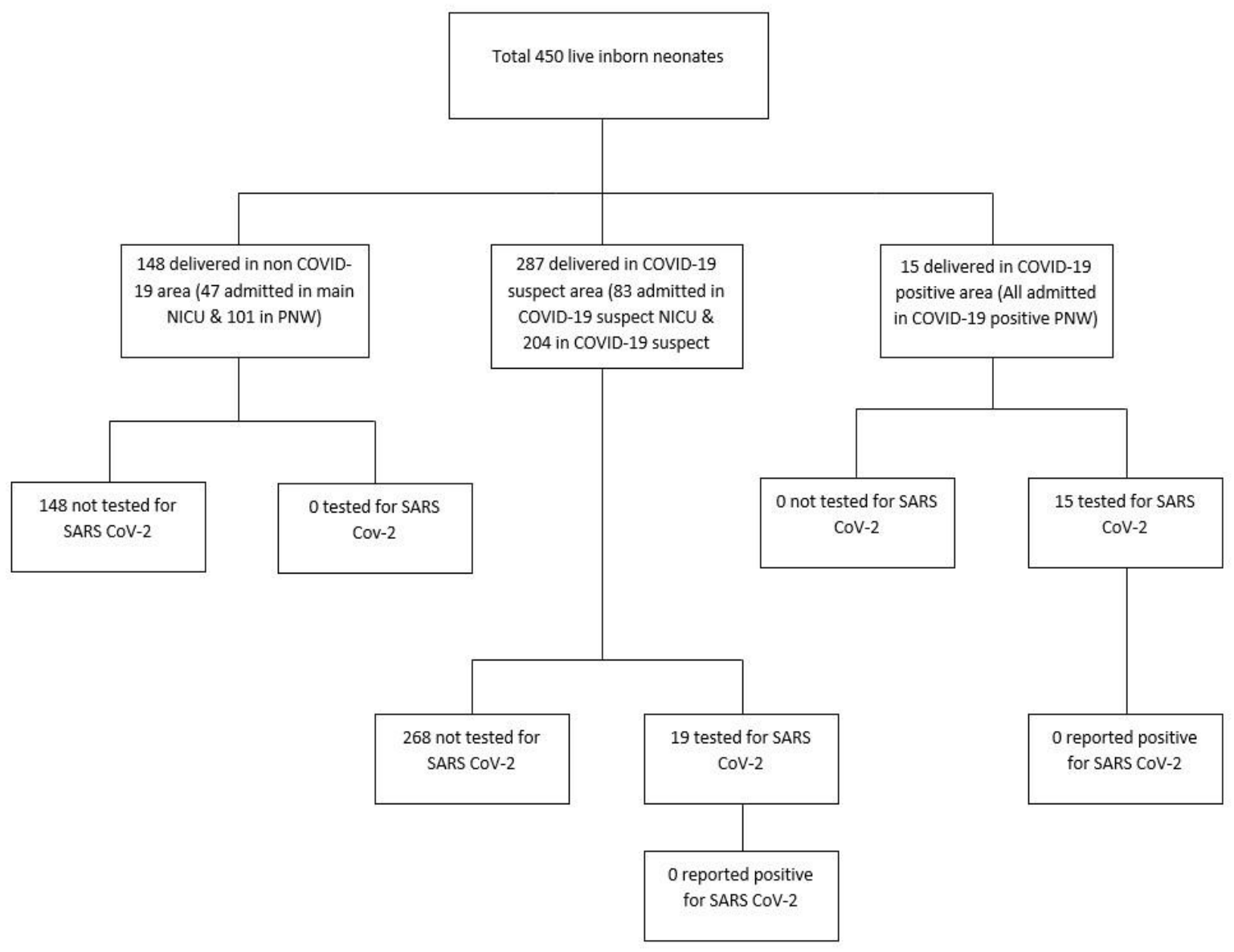

Figure 2: Total number of deliveries conducted in various hospital areas and their SARS Cov-2 status.

\section{CONCLUSION}

The current paper discussed the problems we encountered while setting up the different pathways of care. High quality tertiary neonatal care is usually centralised to a few centres in most LMICs with perennial problems of access and burden of patient overload. These problems are expected to be amplified by the pandemic. Our experience shows that inpatient care can be preserved even in the current pandemic situation with some stress on the existing infrastructure and manpower due to division into three different areas from the usual one. However, early discharge to accommodate increasing new admissions and poor physical follow up remains a problem. These differences in follow up rates are as expected from the experience gained from previous epidemics in LMICs. This necessitates pro-active measures at all levels of care; primary, secondary and tertiary; to improve rate of follow up and increase dependence on tele-medicine to prevent the occurrence of eventualities.

Funding: No funding sources

Conflict of interest: None declared

Ethical approval: Not required

\section{REFERENCES}

1. WHO. Fact sheet: Pneumonia of unknown causeChina. Available at: http://www.who.int/csr/don/05january-2020-pneumonia-of-unkown-causechina/en/. Accessed on 10 February 2021.

2. Zhu N, Zhang D, Wang W, Li X, Yang B, Song J, et al. A Novel Coronavirus from Patients with Pneumonia in China, 2019. N Engl J Med. 2020;382(8):727-33.

3. Gorbalenya AE, Baker SC, Baric RS, de-Groot RJ, Drosten C, Gulyaeva AA, et al. Severe acute 
respiratory syndrome-related coronavirus: The species and its viruses- a statement of the Coronavirus Study Group. Biorxiv. 2020.

4. WHO Director-General's opening remarks at the media briefing on COVID-19, 2020. Available at: https://www.who.int/director-

general/speeches/detail/who-director-general-sopening-remarks-at-the-media-briefing-on-covid19. Accessed on 11 March 2020.

5. Kaushik S, Kaushik S, Sharma Y, Kumar R, Yadav JP. The Indian perspective of COVID-19 outbreak. Virus Dis. 2020;31:146-53.

6. WHO. Fact sheet: Coronavirus Disease (COVID19), 2021. Available at: https://covid19.who.int. Accessed on 10 February 2021.

7. $\mathrm{Wu} \mathrm{Z}$, McGoogan JM. Characteristics of and important lessons from the coronavirus disease 2019 (covid-19) outbreak in China: summary of a report of 72314 cases from the chinese center for disease control and prevention. JAMA. 2020;323(13):123942.

8. Livingston E, Bucher K. Coronavirus Disease 2019 (COVID-19) in Italy. JAMA. 2020;323:1335.

9. Liguoro I, Pilotto C, Bonanni M, Ferrari ME, Pusiol A, Nocerino A, et al. SARS-COV-2 infection in children and newborns: a systematic review. Eur J Pediatr. 2020;1-18.

10. Wang Y, Wang Y, Chen Y, Qin Q. Unique epidemiological and clinical features of the emerging 2019 novel coronavirus pneumonia (COVID-19) implicate special control measures. J Med Virol. 2020;92(6):568-76.

11. Dong Y, Mo X, Hu Y, Qi X, Jiang F, Jiang Z, et al. Epidemiology of COVID-19 Among Children in China. Pediatrics. 2020;145(6):20200702.

12. Huang C, Wang Y, Li X, Ren L, Zhao J, Hu Y, et al. Clinical features of patients infected with 2019 novel coronavirus in Wuhan, China. Lancet. 2020;395(10223):497-506.

13. Cao Q, Chen YC, Chen CL, Chiu CH. SARS-CoV2 infection in children: Transmission dynamics and clinical characteristics. J Formos Med Assoc. 2020;119(3):670-3.

14. Sochas L, Channon AA, Nam S. Counting indirect crisis-related deaths in the context of a lowresilience health system: the case of maternal and neonatal health during the Ebola epidemic in Sierra Leone. Health Policy Plan. 2017;32:32-9.

15. Chang HJ, Huang N, Lee CH, Hsu YJ, Hsieh CJ, Chou YJ. The impact of the SARS epidemic on the utilization of medical services: SARS and the fear of SARS. Am J Public Health. 2004;94(4):562-4.

16. Elston JWT, Cartwright C, Ndumbi P, Wright J. The health impact of the 2014-15 Ebola outbreak. Public Health. 2017;143:60-70.

17. Roberton T, Carter ED, Chou VB, Stegmuller AR, Jackson BD, Tam Y, et al. Early estimates of the indirect effects of the COVID-19 pandemic on maternal and child mortality in low-income and middle-income countries: a modelling study. Lancet Glob Health. 2020;8(7):901-8.

18. UNICEF. Fact sheet: India (IND): Demographics, health and infant mortality. Available at: https://data.unicef.org/country/ind/. Accessed on 11 February 2021.

19. Chawla D, Chirla D, Dalwai S, Deorari AK, Ganatra A, Gandhi A, et al. Perinatal-neonatal management of covid-19 infection - guidelines of the federation of obstetric and gynaecological societies of india (fogsi), national neonatology forum of india (nnf) and indian academy of pediatrics (IAP). Indian Pediatr. 2020;57(6):536-48.

20. Ministry of health and family welfare directorate general of health services. fact sheet: novel coronavirus disease 2019 (COVID-19): guidelines on rational use of personal protective equipment Available https://www.mohfw.gov.in/pdf/Guidelinesonrational useofPersonalProtectiveEquipment.pdf. Accessed on 12 February 2021.

21. MOHFW. Fact sheet: Advisory on Social Distancing Measure in view of spread of COVID-19 disease. Available at: https://www.mohfw.gov.in/pdf/SocialDistancingAd visorybyMOHFW.pdf. Accessed on 13 February 2021.

22. Chandrasekharan $\mathrm{P}$, Vento $\mathrm{M}$, Trevisanuto $\mathrm{D}$, Partridge E, Underwood MA, Wiedeman J, et al. Neonatal Resuscitation and Postresuscitation Care of Infants Born to Mothers with Suspected or Confirmed SARS-CoV-2 Infection. Am J Perinatol. 2020;37(80:813-24.

23. Wyckoff MH, Aziz K, Escobedo MB, Kapadia VS, Kattwinkel J, Perlman JM, et al. Part 13: Neonatal Resuscitation: 2015 American Heart Association guidelines update for cardiopulmonary resuscitation and emergency cardiovascular care. Pediatrics. 2015;136:196-218.

24. CDC. Fact sheet: Evaluation and Management Considerations for Neonates At Risk for COVID19. Available at: https://www.cdc.gov/coronavirus/2019ncov/hcp/caring-for-newborns.html. Accessed on 15 February 2021.

25. WHO. Fact sheet: Breastfeeding and COVID-19. Available at: https://www.who.int/newsroom/commentaries/detail/breastfeeding-and-covid19. Accessed on 11 February 2021.

26. Davanzo R, Moro G, Sandri F, Agosti M, Moretti C, Mosca F. Breastfeeding and coronavirus disease2019: Ad interim indications of the Italian Society of Neonatology endorsed by the Union of European Neonatal \& Perinatal Societies. Matern Child Nutr. 2020;16(3):13010.

27. Ferioli M, Cisternino C, Leo V, Pisani L, Palange P, Nava S. Protecting healthcare workers from SARSCoV-2 infection: practical indications. Eur Respir Rev. 2020;29:200068. 
28. Tran K, Cimon K, Severn M, Pessoa-Silva CL, Conly J. Aerosol generating procedures and risk of transmission of acute respiratory infections to healthcare workers: a systematic review. PLoS ONE. 2012;7:35797.

29. Chan MTV, Chow BKM, Chu L, Hui DSC. Mask Ventilation and Dispersion of Exhaled Air. Am J Respir Crit Care Med. 2013;187(7):12-4.

30. Fowler RA, Guest CB, Lapinsky SE, Sibbald WJ, Louie M, Tang P, et al. Transmission of severe acute respiratory syndrome during intubation and mechanical ventilation. Am J Respir Crit Care Med. 2004;169(11):1198-202.

31. Shalish W, Lakshminrusimha S, Manzoni P, Keszler M, Sant'Anna GM. COVID-19 and Neonatal Respiratory Care: Current Evidence and Practical Approach. Am J Perinatol. 2020;37(8):780-91.

32. Campbell-Yeo M, Disher T, Benoit B, Johnston C. Understanding kangaroo care and its benefits to preterm infants. Pediatric Health Med Ther. 2015; 6:15-32.

33. National Health Mission. Fact sheet: Immunization. Available at: https://nhm.gov.in/index 1.php?lang=1\&level=2\&su blinkid $=824 \& l i d=220$. Accessed on 10 February 2021.

34. Salvatore CM, Han JY, Acker KP, Tiwari P, Jin J, Brandler $M$, et al. Neonatal management and outcomes during the COVID-19 pandemic: an observation cohort study. Lancet Child Adolesc Health. 2020;2352(20):30235-2.

Cite this article as: Grover R, Shubham S, Basu S. Strategies for neonatal care during the COVID-19 pandemic: a lower middle-income country (LMIC) perspective. Int J Contemp Pediatr 2021;8:950-7. 